\title{
Pengaruh kinerja petugas kesehatan pada tingkat kepuasan pasien
}

\author{
Muhammad Nurhidayat ${ }^{1}$, M. Arifki Zainaro ${ }^{2 *}$
}

1Puskesmas Batu Ketulis Kabupaten Lampung Barat. Email: mnurhidayat872@gmail.com

2Universitas Malahayati Bandar Lampung. *Email: m.arifkiz@yahoo.com

Abstract

The performance of health workers and patient satisfaction

Background: Patient satisfaction related to the quality of health services by knowing the level of patient satisfaction, puskesmas can improve service quality. The percentage of patients who expressed satisfaction with the service based on the results of the survey with standard instruments. HR performance is a term derived from the word Job Performance or Actual Performance (work performance or actual achievement achieved by someone)

Purpose: To determine the effect of the performance of health workers on patient satisfaction in Public health centers.

Method: A quantitative with the design correlative. The population were patients who were inpatient at 7 Public Health Centers in West Lampung District, with a total sample of 130 respondents. Sampling in this study using the Cluster Sampling method (Sample Area)

Results: Most respondents rated the performance of health workers in the poor category of 78 respondents $(60.0 \%)$ and the majority of respondents were dissatisfied numbered 69 respondents $(53.1 \%)$. Based on the results of statistical tests, $p$-value 0.034 or $p$-value $<a(0.05)$ is obtained, which means there is a relationship between health worker performance and patient satisfaction.

Conclusion: The results of this study are expected that the Public health centre management can improve the performance of nurses and can develop or update the best quality of service for patients, by providing facilities, facilities and infrastructure to support health services, improve all quality service procedures and improve performance related programs, and by improving health status, so that patient satisfaction can be improved.

\section{Keywords: The performance; Health workers; Patient satisfaction}

Pendahuluan : Kepuasan pasien yang berhubungan dengan mutu pelayanan kesehatan dengan mengetahui tingkat kepuasan pasien, puskesmas dapat meningkatkan mutu pelayanan. Persentasi pasien yang menyatakan puas terhadap pelayanan berdasarkan hasil survey dengan instrument yang baku. Kinerja SDM merupakan istilah yang berasal dari kata Job Performance atau Actual Performance (prestasi kerja atau prestasi sesungguhnya yang dicapai seseorang)

Tujuan : Diketahui pengaruh kinerja petugas kesehatan terhadap kepuasan pasien Di Puskesmas Se-Kabupaten Lampung Barat Tahun 2019.

Metode : Kuantitatif dengan desain yang digunakan dalam penelitian ini adalah korelatif. Populasi dalam penelitian ini adalah pasien yang datang berobat/dirawat pada Puskesmas Se-Kabupaten Lampung Barat, dengan jumlah sampel di 7 Puskesmas berjumlah 130 responden. Pengambilan sampel dalam penelitian ini menggunakan metode Cluster Sampling (Area Sampel)

Hasil : Sebagian besar responden menilai kinerja petugas kesehatan dalam kategori buruk berjumlah 78 responden $(60,0 \%)$ dan sebagian besar responden merasa tidak puas berjumlah 69 responden $(53,1 \%)$. Berdasarkan hasil uji statistik, didapatkan $p$-value 0,034 atau $p$-value < nilai a $(0,05)$ yang artinya terdapat hubungan antara kinerja petugas kesehatan dengan kepuasan pasien.

Simpulan: Hasil penelitian ini diharapkan agar pihak Puskesmas dapat meningkatkan kinerja perawat dan dapat mengembangkan atau memperbaharui kualitas pelayanan yang terbaik untuk pasien, dengan cara menyediakan fasilitas, sarana dan prasarana dalam menunjang pelayanan kesehatan, memperbaiki semua tatacara pelayanan yang bermutu serta meningkatkan program kinerja yang berhubungan dengan peningkatan status kesehatan, sehingga kepuasan pasien dapat ditingkatkan.

Kata Kunci: Kinerja; Petugas kesehatan; Kepuasan pasien 


\section{PENDAHULUAN}

Kepuasan pasien merupakan salah satu indikator penting yang harus diperhatiakan dalam pelayanan kesehatan. Kepuasan pasien adalah hasil penilaian dari pasien terhadap pelayanan kesehatan dengan membandingkan apa yang diharapkan sesuai dengan kenyataan pelayanan kesehatan yang diterima disuatu tatanan kesehatan (Parendreng, \& Tasnim, 2019; Budhiarta \& Muttaqin, 2019).

Beberapa hasil penelitian menunjukkan data tentang tingkat kepuasan pasien diberbagai negara, tahun 2013 di Kenya menyatakan 40,4\%, kepuasan pasien di India tahun 2009 adalah 34,4 $\%$, sedangkan di Indonesia menunjukkan angka kepuasan pasien, $42,8 \%$ di Maluku Tengah dan Sumatra Barat 44,4\% (Riska, 2017; Kumari, Idris, Bhushan, Khanna, Agarwal, \& Singh, 2009; Ndambuki, 2013).

Standar kepuasan pasien di pelayanan kesehatan ditetapkan secara nasional oleh departemen kesehatan menurut permenkes tahun 2019 tentang standar pelayanan minimal kepuasan pasien yaitu $100 \%$. Bila ditemukan pelayanan kesehatan dengan tingkat kepuasan pasien berada dibawah $100 \%$ maka dianggap pelayanan kesehatan yang diberikan tidak memenuhi standar minimal atau tidak berkualitas (Sondari, 2015; Kalsum, 2016; Kementerian Kesehatan Republik Indonesia, 2019). Indikator Standar Pelayanan rawat jalan : Ketepatan waktu jam buka pelayanan $95 \%$, Waktu tunggu rawat jalan 30 menit, tidak terjadinya kesalahan identifikasi pasien $100 \%$, tidak terjadinya rujukan rawat jalan pasien yang semestinya dapat ditangani di puskesmas $100 \%$. Pelayanan Ruang Gawat Darurat : waktu tanggap 5 menit, tidak terjadinya kesalahan prosedur tindakan medis $100 \%$, kelengkapan informed consent sebelum melaksanakan prosedur tindakan medis $100 \%$.Pelayanan rawat inap : tidak terjadinya pasien jatuh $100 \%$, kejadian infeksi nosokomial $9 \%$, pelayanan obat waktu tunggu pelayanan obat jadi 30 menit, waktu tunggu pelayanan obat racikan 45 menit, peresepan obat sesuai formularium nasional $100 \%$, tidak terjadinya kesalahan pemberian obat100 \%. Pelayanan rekam medis : Kelengkapan pengisian rekam medis100 \%, ketepatan waktu pelaporan ke Dinas Kesehatan $100 \%$, pengendalian infeksi : kepatuhan hand hygiene100 \%, ketaatan penggunaan APD $100 \%$ (Wijaya, 2016; Syah,
2018; Kementerian Kesehatan Republik Indonesia, 2019). Pemeliharaan sarana dan prasarana pelayanan : ketepatan waktu pemeliharaan alat sesuai jadual yang disusun $80 \%$, ketepatan waktu kalibrasi alat $90 \%$, Pelayanan nutrisi rawat inap : ketepatan waktu pemberian makan pada pasien rawat inap $100 \%$, pemberian makan sesuai asuhan gizi $100 \%$, penyediaan linen : ketepatan waktu penyediaan linen $100 \%$ (Amir, 2018; Ginting, 2019; Kementerian Kesehatan Republik Indonesia, 2019). Perawat merupakan salah satu tenaga kerja yang memegang peranan penting dalam pelayanan kesehatan di tingkat pelayanan kesehatan. Perawat memiliki peran asuhan keperawatan yang berkualitas karena perawat berinteraksi langsung dengan pasien sehingga pearawat harus mampu memberikan peyanan kepearawatan yang bermutu agar meningkatkan angka kepuasan pasien (Noorkasiani, Heryati, \& Rita, 2009). Kepuasan pasien ditentukan oleh beberapa faktor antara lain, yaitu : Kualitas produk atau jasa, harga, emosional, kinerja, estetika, karakteristik produk, pelayanan, lokasi, pasilitas, suasana, desain visual (Khamida \& wastiah, 2015; Radito, 2014). Secara garis besar ada beberapa faktor yang berpegaruh pada kepuasan konsumen/pengguna jasa pelayanan kesehatan dikategorikan dalam 5 kategori yaitu Kualitas Produk/Product Quality adalah bagaimana konsumen akan merasa puas atas produk jasa yang digunakan, beberapa dimensi yang membentuk kualitas produk barang adalah Ferformence, realibility, conformance, durability, feature dan lain-lain. Kualitas Pelayanan Service Quality adalah bagaiman konsumen akan puas dengan jasa yang telah dikonsumsi. Dimensi Service Quality meliputi 5 dimensi yaitu : tangible, reability, assurance, empathy, responsiveness. Skala nilai dinyatakan dengan skala 1-5. Skala 1 adalah tidak puas dan skala 5 adalah puas. Nilai rerata skala adalah skor (skor=jumlah $\mathrm{n}$ pengukuran dikatakan skala). Empati (sikap peduli) yang ditunjukkan oleh petugas kesehatan. Harga/Price adalah harga dari produk, jasa yang diukur dari value (nilai) manfaat dibandingkan dengan biaya yang dikeluarkan konsumen. Harga adalah harga pelayanan medis (medical care) yanh harus dibayar konsumen (price is that which is given in an exchange to equire a good or service). Faktor Emosional/Emotional Factor adalah keyakinan dan rasa bangga terhadap produk, jasa

M. Arifki Zainaro*, Muhammad Nurhidayat ${ }^{2}$

'Program D III Keperawatan Universitas Malahayati Bandar Lampung. *Email: m.arifkiz@yahoo.com

${ }^{2}$ Puskesmas Batu Ketulis Kabupaten Lampung Barat. Email: mnurhidayat872@gmail.com 
yang digunakan dibandingkan dengan pasaing. Emotional Factor di ukur dari preceved best score, artinya persepsi kualitas terbaik dibandingkan dengan pesaingnya. Biaya/Cost of Aquiring ; Biaya yang dikeluarkan untuk mendapatkan produk atau jasa.yang dikeluarkan (Dwihapsari \& Santosa, 2016; Fitriyana, 2017).

Kinerja SDM merupakan istilah yang berasal dari kata Job Perfaormance atau Actual Perfaormance(prestasi kerja atau prestasi sesungguhnya yang dicapai seseorang). Definisi kinerja yang dikemukakan oleh Bambang Kusriyanto adalah "Perbandingan hasil yang dicapai dengan peran serta tenaga kerja persatuan waktu (lazimnya perjam)" (Gunawan, 2015; Fajrin \& Susilo, 2018).

Penelitian di Rumah Sakit Pertamina Bintang Amin Bandar Lampung tahun 2016 dari 77 responden dengan kinerja perawat baik sebanyak 45 responden $(58,4 \%)$ merasa puas dan 32 responden $(41,6 \%)$ merasa tidak puas. Sedangkan dari 65 responden dengan kinerja perawat tidak baik sebanyak 19 responden $(29,2$ $\%)$ menyatakan puas dan 46 responden $(70,8 \%)$ menyatakan tidak puas. Hasil Uji chi square didapatkan nilai $p$ value 0,001 , artinya lebih kecil dibandingkan ndengan nilai alpha $(0,001<0,05)$. Dengan demikian dapat disimpulkan secara statistik dengan derajat kepercayaan $95 \%$, diyakini terdapat pengaruh besar antara kinerja petugas kesehatan dengan tingkat kepuasan pasien (Ayu, 2016).

Hasil prasurvey di Puskesmas Se-Kabupaten Lampung Barat tahun 2018 hasil survey kepuasan masyarakat bahwa dari 100 orang responden, diketahui 81 responden $(81,71 \%)$ mengatakan puas, 19 responden (18,29\%) menyatakan kurang puas terhadap pelayanan kesehatan di puskesmas Se-Kabupaten Lampung Barat. Namun dua hal yang kurang mengembirakan adalah indikator kecepatan dalam pelayanan $(78,75 \%)$, yaitu target waktu pelayanan dapat disesuaikan dalam waktu yang telah ditentukan oleh unit penyelenggara pelayanan kesehatan contoh pada loket pendaftaran waktu 3-5 menit, loket pengambilan obat 5-7 menit dan indikator ketepatan waktu pelayanan berobat di puskesmas Se-Kabupaten
Lampung Barat $(78,50 \%)$, yaitu pelaksanaan waktu pelayanan sesuai dengan ketentuan yang telah ditetapkan misal balai pengobatan umum yang dijadwalkan mulai pelayanan pada pukul 07.45 ternyata dimulai pada pukul 08.00 , terlihat bahwasanya hasil tersebut belum mencapai standar pelayanan minimal yang ditetapkan oleh Kementrian Kesehatan Republik Indonesia.

Angka kepuasan pasien yang belum sesuai dengan target kepuasan pasien di puskesmas SeKabupaten Lampung Barat akan berdampak terhadap perkembangan puskesmas itu sendiri. Pada pasien yang merasa tidak puas terhadap pelayanan kesehatan yang diterima maka pasien memutuskan akan pindah ke pelayanan kesehatan yang lain yang dapat memberikan pelayanan kesehatan yang lebih baik (Rini, 2019). Dengan demikian kurangnya kepuasan pasien dapat menimbulkan hilangnya kepercayaan pasien terhadap pelayanan kesehatan tersebut. Dari data diatas, penulis tertarik untuk mengambil judul “ Pengaruh Kinerja Petugas Kesehatan Terhadap Tingkat Kepuasan Pasien"

\section{METODE PENELITIAN}

Desain korelatif Cross Sectional dengan populasinya adalah rata-rata pasien yang datang berobat / dirawat dalam satu bulan. Sesuai data di tahun 2018, dengan jumlah rata-rata perbulan 193 pasien. Sampel yang digunakan dalam penelitian ini adalah pasien Puskesmas Batu Ketulis Kabupaten Lampung Barat, terbagi menjadi 7 Puskesmas yang ada di Kabupaten Lampung Barat, dengan jumlah sampel 130 responden. Variabel dependennya kepuasan pasien dengan penilaian kategori yaitu puas dan tidak puas. Variabel independen yaitu kinerja petugas kesehatan dengan kategori penilian baik dan buruk. Instrument kedua varibel sudah dilakukan uji validitas dan reliablitas dengan hasil Cronbach's Alpa 0.974. Uji etik penelitian yang dilakukan di Komisi Etik Penelitian Kesehatan Universitas Malahayati dengan nomor surat 549/EC/KEPUNMAL/VII/2019. Untuk pengolahan data penelitian dilakukan dengan menggunakan aplikasi SPSS versi 20.

M. Arifki Zainaro*, Muhammad Nurhidayat ${ }^{2}$

'Program D III Keperawatan Universitas Malahayati Bandar Lampung. *Email: m.arifkiz@yahoo.com

${ }^{2}$ Puskesmas Batu Ketulis Kabupaten Lampung Barat. Email: mnurhidayat872@gmail.com 
HASIL

Tabel 1. Karakteristik Responden $\mathrm{N}=130$

\begin{tabular}{lcc}
\hline Variabel & Frekuensi (f) & Persentase (\%) \\
\hline Usia & & \\
$<35$ & 51 & 39.2 \\
$>35$ & 79 & 60.8 \\
Jenis Kelamin & & \\
Laki-laki & & \\
Perempuan & 55 & 42.3 \\
& 75 & 57.7 \\
Pendidikan & & \\
SD-SMP & & \\
SMA & 33 & 25.4 \\
Sarjana & 85 & 65.3 \\
& 12 & 9.3 \\
\hline
\end{tabular}

Tabel 2. Distribusi Frekwensi Penilaian Responden $\mathrm{N}=130$

\begin{tabular}{lcc}
\hline \multicolumn{1}{c}{ Variabel } & Frekuensi (f) & Persentase (\%) \\
\hline $\begin{array}{l}\text { Kinerja Petugas } \\
\text { Kesehatan }\end{array} \quad$ & \\
$\quad$ Baik & 52 & 40.0 \\
$\quad$ Buruk & 78 & 60.0 \\
$\begin{array}{l}\text { Kepuasan Pasien } \\
\quad \text { Puas }\end{array}$ & 61 & 46.9 \\
$\quad$ Tidak Puas & $\underline{69}$ & $\underline{53.1}$ \\
\hline
\end{tabular}

Berdasarkan tabel 2, diketahui bahwa sebagian besar responden mempunyai kinerja yang buruk berjumlah 78 responden $(60,0 \%)$. Diketahui sebagian besar responden tidak puas berjumlah 69 responden $(53,1 \%)$.

Table 3. Hubungan Kinerja Petugas Kesehatan Terhadap Kepuasan Pasien

\begin{tabular}{|c|c|c|c|c|c|c|c|c|}
\hline \multirow{3}{*}{$\begin{array}{l}\text { Kinerja } \\
\text { Petugas } \\
\text { Kesehatan }\end{array}$} & \multicolumn{4}{|c|}{ Kepuasan } & \multicolumn{2}{|c|}{ Total } & \multirow[t]{3}{*}{$P$-Value } & \multirow{3}{*}{$\begin{array}{c}\text { OR (Cl } \\
95 \%)\end{array}$} \\
\hline & \multicolumn{2}{|c|}{ Puas } & \multicolumn{2}{|c|}{ Tidak Puas } & & & & \\
\hline & $\mathrm{n}$ & $\%$ & $\mathrm{n}$ & $\%$ & $\mathbf{N}$ & $\%$ & & \\
\hline Baik & 18 & 13.8 & 34 & 26.2 & 52 & 40 & 0.034 & 0.431 \\
\hline Buruk & 43 & 33.1 & 35 & 26.9 & 78 & 60 & & $(0.209-$ \\
\hline Total & 61 & 46.9 & 69 & 53.1 & 130 & 100.0 & & $0.890)$ \\
\hline
\end{tabular}

Berdasarkan tabel 3, diketahui ada 52 responden yang mempunyai kinerja baik, dimana terdapat 18 responden $(34,6 \%)$ merasa puas, dan 34 responden $(65,4 \%)$ merasa tidak puas, sedangkan terdapat 78 responden yang mempunyai kerja buruk, dimana 43 responden (55,1\%) merasa puas, dan 35 responden (44,9\%) merasa tidak puas. Berdasarkan hasil uji statistik, didapatkan $p$-value 0,034 atau $p$-value < nilai a $(0,05)$ yang artinya terdapat hubungan antara

M. Arifki Zainaro**, Muhammad Nurhidayat ${ }^{2}$

'Program D III Keperawatan Universitas Malahayati Bandar Lampung.*Email: m.arifkiz@yahoo.com

2Puskesmas Batu Ketulis Kabupaten Lampung Barat. Email: mnurhidayat872@gmail.com 
Pengaruh kinerja petugas kesehatan pada tingkat kepuasan pasien

kinerja petugas kesehatan dengan kepuasan pasien dengan nilai OR sebesar 0,431 yang artinya responden yang mempunyai kinerja kurang baik berpeluang 0,431 kali lebih besar untuk mengalami kepuasan yang kurang baik.

\section{PEMBAHASAN}

\section{Kinerja Petugas Kesehatan}

Berdasarkan hasil penelitian, diketahui bahwa, sebagian besar responden mempunyai kinerja yang tidak baik berjumlah 78 responden $(60,0 \%)$. Filosofi dan spirit tentang kinerja sudah ada sejak awal peradaban manusia karena makna kinerja adalah keinginan (the will) dan upaya (effort) manusia untuk selalu meningkatkan kualitas kehidupan dan penghidupan disegala bidang. Secara konseptual, kinerja adalah hubungan antara keluaran atau hasil organisasi dengan masukan yang diperlukan. Kinerja dapat dikuantifikasi dengan membagi keluaran dan masukan. Menaikan produktivitas dapat dilakukan dengan memperbaiki rasio kinerja, dengan menghasilkan lebih banyak keluaran atau output yang lebih baik dengan tingkat masukan sumber daya tertentu (Indriyani, 2012). Hasil penelitian ini sejalan dengan penelitian Bachtiar 2016 tentang Hubungan Motivasi Dengan Kinerja Tenaga kesehatan Di Puskesmas Batua Kecamatan Manggala Kota Makassar, menyebutkan bahwa Hasil penelitian menunjukkan bahwa ada hubungan antara fisiologis dengan kinerja tenaga kesehatan di Puskesmas Batua dengan nilai $p=0,013$ (nilai $p<0,05)$, ada hubungan antara keamanan kerja dengan kinerja tenaga kesehatan di Puskesmas Batua Kecamatan dengan nilai $p=0,000$ (nilai $p<0,005)$, dan ada hubungan antara penghargaan dengan kinerja tenaga kesehatan di Puskesmas Batua dengan nilai $p=0,000$ (nilai $p<0,005$ ). Diharapkan kepada tenaga kesehatan agar meningkatkan kinerja sehingga mutu pelayanan puskesmas terhadap masyarakat akan semakin baik.

Berdasarkan hasil penelitian diketahui bahwa sebagia besar responden tidak mempunyai kinerja yang kurang baik, hal ini dikarenakan kurangnya motivasi serta sikap dalam melakukan pekerjaan, yaitu karena faktor beban kerja, stres kerja serta kurangnya reward atau penghargaan yang diberikan oleh pimpinan.

\section{Kepuasan Pasien}

Sebagian besar responden tidak puas berjumlah 69 responden $(53,1 \%)$. Hasil penelitian ini sejalan dengan teori Kotler (2009), kepuasan pasien merupakan salah satu indikator penting yang harus diperhatikan dalam pelayanan kesehatan. Kepuasan pasien adalah hasil penilaian dari pasien terhadap pelayanan kesehatan dengan membandingkan apa yang diharapkan sesuai dengan kenyataan pelayanan kesehatan yang diterima disuatu tatanan kesehatan rumah sakit. Dengan demikian kepuasan pasien dirumah sakit tergantung bagaimana pelayanan yang diberikan oleh pihak rumah sakit tersebut. Namun pelayanan yang diberikan masih ada yang belum sesuai dengan apa yang diinginkan oleh pasien dan kepuasan pasien masih belum sesuai dengan standar (Wildan, Yuswadi, Wahono, \& Puspitaningtyas, 2015).

Hasil penelitian ini sejalan dengan penelitian Mailani \& Fitri 2017, tentang Hubungan Perilaku Caring Perawat Dengan Tingkat Kepuasan Pasien BPJS Di RSUD DR. Rasidin Padang, menyebutkan bahwa hasil penelitian didapatkan sebagian besar $39(46,4 \%)$ perilaku caring perawat buruk, lebih dari separuh $50(59,5 \%)$ responden tidak puas dengan perilaku caring perawat.

Berdasarkan hasil penelitian yang peneliti lakukan diketahui bahwa sebagian besar pasien tidak mengatakan puas, hal ini disebabkan oleh beberapa faktor seperti fasilitas, sarana dan prasarana yang kurang, seperti kurangnya alat medis, toilet kurang bersih, kurangnya kursi roda, kurangnya brangkar, terbatasnya obat, serta terbatasnya tempat tidur bagi pasien rawat inap.

\section{Hubungan Kinerja Petugas Kesehatan Terhadap Kepuasan Pasien}

Berdasarkan hasil penelitian, diketahui bahwa ada 52 responden yang mempunyai kinerja baik, dimana terdapat 18 responden $(34,6 \%)$ merasa puas, dan 34 responden $(65,4 \%)$ merasa tidak puas, sedangkan terdapat 78 responden yang mempunyai kerja tidak baik, dimana 43 responden (55,1\%) merasa puas, dan 35 responden (44,9\%) merasa tidak puas. Berdasarkan hasil uji statistik, didapatkan $p$-value 0,034 atau $p$-value $<$ nilai $a$ $(0,05)$ yang artinya terdapat hubungan antara kinerja petugas kesehatan dengan kepuasan pasien dengan nilai OR sebesar 0,431 yang artinya responden yang mempunyai kinerja kurang baik

M. Arifki Zainaro*, Muhammad Nurhidayat ${ }^{2}$

'Program D III Keperawatan Universitas Malahayati Bandar Lampung. *Email: m.arifkiz@yahoo.com

${ }^{2}$ Puskesmas Batu Ketulis Kabupaten Lampung Barat. Email: mnurhidayat872@gmail.com 
Pengaruh kinerja petugas kesehatan pada tingkat kepuasan pasien

berpeluang 0,431 kali lebih besar untuk mengalami kepuasan yang kurang baik.

Kepuasan pasien yang berhubungan dengan mutu pelayanan kesehatan dengan mengetahui tingkat kepuasan pasien, puskesmas dapat meningkatkan mutu pelayanan. Persentasi pasien yang menyatakan puas terhadap pelayanan berdasarkan hasil survey dengan instrument yang baku (Ningrum \& Huda. (2014). Kinerja SDM merupakan istilah yang berasal dari kata Job Perfaormance atau Actual Perfaormance(prestasi kerja atau prestasi sesungguhnya yang dicapai seseorang). Definisi kinerja yang dikemukakan oleh Bambang Kusriyanto adalah "Perbandingan hasil yang dicapai dengan peran serta tenaga kerja persatuan waktu (lazimnya perjam)" (Khamida, \& Mastiah, 2015).

Hasil penelitian ini sejalan dengan penelitian Shinta Arini Ayu tahun 2016 di Rumah Sakit Pertamina Bintang Amin Bandar Lampung tahun 2016 dari 77 responden dengan kinerja perawat baik sebanyak 45 responden $(58,4 \%)$ merasa puas dan 32 responden $(41,6 \%)$ merasa tidak puas. Sedangkan dari 65 responden dengan kinerja perawat tidak baik sebanyak 19 responden $(29,2 \%)$ menyatakan puas dan 46 responden $(70,8 \%)$ menyatakan tidak puas. Hasil Uji chi square didapatkan nilai $p$ value 0,001 , artinya lebih kecil dibandingkan ndengan nilai alpha $(0,001<0,05)$. Dengan demikian dapat disimpulkan secara statistikdengan derajat kepercayaan $95 \%$, diyakini terdapat pengaruh besar antara kinerja petugas kesehatan dengan tingkat kepuasan pasien.

Berdasarkan hasil penelitian diatas, maka menurut analisis peneliti bahwa sebagain besar responden mempunyai kinerja yang kurang baik, namun masih ada pasien yang merasa puas, hal ini dikarenakan pelayanan yang baik dan sarana serta fasilitas yang mendukung, sedangkan terdapat petugas kesehatan yang mempunyai kinerja baik, namun masih ada yang tidak puas, hal ini dikarenakan faktor pelayanan yang kurang baik serta biaya yang terlalu mahal serta proses semua pelayanan yang lama.

\section{Keterbatasan Penelitian}

Instrument yang peneliti gunakan seharusnya mengacu pada tenaga kesehatan berdasarkan penilaian responden kepada tenaga kesehatan. Pada lembar instrument penelitian, seharusnya pernyataan pada setiap soal harus dipisah berdasarkan tenaga kesehatan rawat inap dan yang bukan rawat inap. Seharusnya dalam menentukan jumlah populasi, peneliti hanya mengambil populasi tenaga kesehatan rawat inap saja, bukan keseluruhan

\section{SIMPULAN}

Berdasarkan hasil penelitian dan pembahasan, maka dapat diambil kesimpulan bahwa, sebagian besar responden mempunyai kinerja yang tidak baik berjumlah 78 responden $(60,0 \%)$, sebagian besar responden tidak puas berjumlah 69 responden (53,1\%). Berdasarkan hasil uji statistik, didapatkan $p$-value 0,034 atau $p$-value $<$ nilai a $(0,05)$ yang artinya terdapat hubungan antara kinerja petugas kesehatan dengan kepuasan pasien Di Puskesmas Se-Kabupaten Lampung Barat Tahun 2019

\section{SARAN}

Hasil penelitian agar dapat dijadikan sebagai acuan penilaian dari kinerja perawat di Puskesmas yang ada Di Kabupaten Lampung Barat untuk memberikan pelayanan keperawatan menjadi lebih baik lagi.

\section{DAFTAR PUSTAKA}

Amir, H. A. P. S. A. H. (2018). Analisis Kualitas Pelayanan Rawat Inap di Rumah Sakit Umum Daerah Kab. Nunukan Kalimantan Utara Periode BPJS tahun 2016.

Ayu, S. A. (2016). "Hubungan Kinerja Perawat Pelaksana dengan Tingkat Kepuasan Pasien Di Ruang Rawat Inap Penyakit Dalam RS Pusat Bintan Amin Bandar Lampung" Jurnal Kesehatan Holistik (The Journal Holistic Healthcare) volume 10, No.4, Oktober $2016: 1$ 4.

Bachtiar, R. (2016). Hubungan pengembangan sumber daya manusia ( $\mathrm{sdm}$ ) dengan kinerja pegawai dalam peningkatan pelayanan kesehatan di puskesmas batua kecamatan manggala kota makassar tahun 2015 (Doctoral dissertation, Univeritas Islam Negeri Alauddin Makassar).

M. Arifki Zainaro', Muhammad Nurhidayat ${ }^{2}$

'Program D III Keperawatan Universitas Malahayati Bandar Lampung.*Email: m.arifkiz@yahoo.com

${ }^{2}$ Puskesmas Batu Ketulis Kabupaten Lampung Barat. Email: mnurhidayat872@gmail.com 
Budhiarta, I., \& Muttaqin, S. (2019). Model HsqMetrix: Untuk Pengukuran Kualitas Pelayanan Kesehatan Dan Rumah Sakit Di Banda Aceh. Cv. Penerbit Qiara Media.

Dwihapsari, B. C., \& Santosa, S. B. (2012). Analisis Pengaruh Kualitas Pelayanan dan Persepsi Harga terhadap Kepuasan Konsumen dalam Menggunakan Jasa Pada Oryza Tour (Doctoral dissertation, Fakultas Ekonomika dan Bisnis).

Fajrin, I. Q., \& Susilo, H. (2018). Pengaruh Gaya Kepemimpinan terhadap Kinerja Karyawan dengan Motivasi Kerja sebagai Variabel Intervening (Studi pada Karyawan Pabrik Gula Kebon Agung Malang). Jurnal Administrasi Bisnis, 61(4), 117-124.

Fitriyana, D. (2017). Pengaruh Kualitas Produk Dan Servicescape Terhadap Kepuasan Konsumen (Survey Pada Konsumen Restoran Pattaya Steamboat Yakiniku Bandung) (Doctoral Dissertation, Fakultas Ekonomi Dan Bisnis Unpas Bandung).

Ginting, D. (2019). Kebijakan penunjang medis rumah sakit (SNARS). Deepublish.

Gunawan, I. (2015). Pengaruh komitmen organisasional dan locus of control terhadap kinerja karyawan pada PT. Nikkatsu Electric Works Bandung. Jurnal Management Undergraduate, 1(1), 1-12.

Kalsum, U. (2016). Hubungan Perilaku Caring Perawat dengan Kepuasan Pasien di Ruang Perawatan Teratai Rumah Sakit Umum Pusat Fatmawati tahun 2016.

Kementerian Kesehatan Republik Indonesia, (2019), Pedoman Pelaksanaa Jaminan Kesehatan Masyarakat, Jakarta: Kemenkes.

Khamida, K., \& Mastiah, M. (2015). Kinerja Perawat Dalam Memberikan Asuhan Keperawatan Berpengaruh Terhadap Kepuasan Pasien Rawat Inap. Journal of Health Sciences, 8(2).
Kumari, R., Idris, M. Z., Bhushan, V., Khanna, A., Agarwal, M., \& Singh, S. K. (2009). Study on patient satisfaction in the government allopathic health facilities of Lucknow district, India. Indian journal of community medicine: official publication of Indian Association of Preventive \& Social Medicine, 34(1), 35.

Mailani, F., \& Fitri, N. (2017). Hubungan Perilaku Caring Perawat dengan Tingkat Kepuasan Pasien BPJS di Ruang Rwat Inap RSUD dr. Rasidin Padang. Jurnal Endurance, 2(2), 203208.

Ndambuki, J. (2013). The level of patients' satisfaction and perception on quality of nursing services in the Renal unit, Kenyatta National Hospital Nairobi, Kenya.

Ningrum, R. M., Huda, N., Kep, M., \& KMB, S. (2014). Hubungan Mutu Pelayanan Kesehatan Bpjs Terhadap Kepuasan Pasien Di Poli Klinik Tht Rumkital Dr. Ramelan Surabaya Oleh.

Noorkasiani, M. K., Heryati, S. K., \& Rita Ismail, S. K. (2009). Sosiologi keperawatan. EGC.

Parendreng, P., \& Tasnim, T. (2019). Kontribusi Bauran Pemasaran Terhadap Keputusan Pasien Untuk Memilih Layanan Kesehatan Di Rumah Sakit Umum Daerah Kabupaten Kolaka Timur. PROMOTIF: Jurnal Kesehatan Masyarakat, 9(2), 159-169.

Radito, T. (2014). Analisis pengaruh kualitas pelayanan dan fasilitas kesehatan terhadap kepuasan pasien Puskesmas. Jurnal IImu Manajemen, 11(2), 1-25.

Rini, D. K. (2019). Efektivitas Pelaksanaan Peraturan Bupati Nomor 24 Tahun 2016 Tentang Program Bantuan Pendidikan Dalam Membantu Peserta Didik Untuk Melanjutkan Ke Perguruan Tinggi Di Kabupaten Tulang Bawang Barat.

Riska, Y.S. (2017). Analisis Tingkat Kepuasan Pasien terhadap Pelayanan Keperawatan dan Faktor-faktor determinannya di ruang rawat Inap RSUD dr. Rasidin Padang Tahun 2017 (Doctoral dissertation, Universitas Andalas).

\section{Arifki Zainaro'*, Muhammad Nurhidayat ${ }^{2}$}

'Program D III Keperawatan Universitas Malahayati Bandar Lampung. *Email: m.arifkiz@yahoo.com

${ }^{2}$ Puskesmas Batu Ketulis Kabupaten Lampung Barat. Email: mnurhidayat872@gmail.com 
Sondari, A. (2015). Analisis Kepuasan Pasien Rawat Jalan Peserta Jaminan Kesehatan Nasional (Jkn) Di Rumah Sakit Umum Daerah (Rsud) Kabupaten Brebes Tahun 2015 (Doctoral dissertation, Universitas Negeri Semarang).

Suarli. S. (2010). Manajemen Keperawatan dengan Pendekatan Praktis. Jakarta: Erlangga.

Syach, W. M. (2018). Implementasi aspek hukum Standar Pelayanan Minimum (SPM) pada pasien Badan Penyelenggara Jaminan Sosial (BPJS) kesehatan tinjauan fatwa Dewan Syariah Nasional MUI no. 107/DSN-MUI/X/106 tentang pedoman penyelenggaraan rumah sakit berdasarkan prinsip syariah studi di Rumah Sakit Umum Daerah Kabupaten Jombang (Doctoral dissertation, Universitas Islam Negeri Maulana Malik Ibrahim).
Wijaya, S. B. R. (2016). Analisis Kebutuhan Tenaga Kerja Berdasarkan Beban Kerja di Loket Pendaftaran BPJS Rumah Sakit Haji Jakarta Tahun 2015 xiiit 94 halaman, 10 tabel, 2 bagan, 4 lampiran (Bachelor's thesis, FKIK UIN Jakarta). 